Research paper

\title{
Montmorillonite as a reinforcement and color stabilizer of gelatin films containing acerola juice
}

\author{
Hálisson L. Ribeiro ${ }^{\mathrm{a}}$, Edy S. Brito ${ }^{\mathrm{b}}$, Men de sá M. Souza Filho ${ }^{\mathrm{b}}$, Henriette M.C. Azeredo ${ }^{\mathrm{b}, \mathrm{c}, *}$

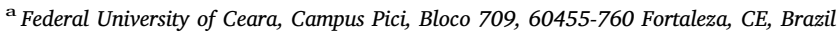 \\ b Embrapa Agroindústria Tropical, R. Dra. Sara Mesquita, 2270-Pici, 60511-110 Fortaleza, CE, Brazil \\ ${ }^{\mathrm{c}}$ Embrapa Instrumentação, R. 15 de Novembro 1452, 13560-970 São Carlos, SP, Brazil
}

\section{A R T I C L E I N F O}

\section{Keywords:}

Clay mineral

Silicates

Cation exchange

Natural pigments

Protein films

\begin{abstract}
A B S T R A C T
Montmorillonite (Mt) is well known as reinforcing agent in films. Moreover, it stabilizes anthocyanin pigments. In this study, Mt has been added as both reinforcement and color stabilizer to gelatin films containing acerola juice. Films were produced with different Mt concentrations ( $0-6.5 \%$ on gelatin). Increasing Mt contents resulted in enhanced tensile strength and modulus, although the elongation has been decreased. Mt also reduced the water vapor permeability in up to $45 \%$. Mt presented two effects on film color: first, it changed its color from yellowish to red; and second, it stabilized film color throughout storage, mainly when added at 3.9\%. It has been suggested that metals from $\mathrm{Mt}$ (such as $\mathrm{Fe}^{3+}$ or $\mathrm{Al}^{3+}$ ) may have formed complexes to anthocyanins, changing and stabilizing their color.
\end{abstract}

\section{Introduction}

Edible films are self-supporting structures produced from edible components, which are usually designed to be used as food wraps, constituting a protective layer additional to the external packaging. Although most proposed edible films are meant not to affect the sensory properties of the wrapped food, films with peculiar sensory properties may be desirable for some specific applications, such as sushi wraps, pizza crust barriers, sachets that melt on cooking, and film snacks (Otoni et al., 2017). In this context, films and coatings added with fruit products (purees or juices) have been particularly well studied (RojasGraü et al., 2007; Azeredo et al., 2012a; Otoni et al., 2014; Azeredo et al., 2016), the fruit flavors and colors contributing to the product acceptability.

Acerola (Malpighia emarginata) is a very popular tropical fruit, thanks to its high ascorbic acid contents, making it one of the richest sources of vitamin C. The anthocyanins cyanidin-3-rhamnoside and pelargonidin-3-rhamnoside are the main responsible for the red color of acerolas (Brito et al., 2007; De Rosso et al., 2008).

Anthocyanins are very prone to degradation, which may be induced by light, oxygen, temperature, and especially $\mathrm{pH}$ changes (McGhie and Walton, 2007; Patras et al., 2010). In aqueous solutions, anthocyanins co-exist as four species in equilibrium - flavylium cation (red, the main form at $\mathrm{pH}<2$ ), quinonoidal base (blue), carbinol or pseudobase (colorless), and chalcone C (colorless) (Pascual-Teresa and Sanchez-
Ballesta, 2008). Some anthocyanins are relatively stable, such as the acylated ones (Guldiken et al., 2017), since acylation promotes an increase in the relative proportion of the flavylium cation (Pascual-Teresa and Sanchez-Ballesta, 2008). On the other hand, some other pigments are especially degradable, including acerola anthocyanins, making the red color of the fruit to dramatically change on processing and storage (Mercali et al., 2013; Mercali et al., 2014), acquiring yellowish or brownish colors. The high degradability of acerola anthocynins has been ascribed to direct condensation of ascorbic acid on C4 of anthocyanins (De Rosso and Mercadante, 2007) and/or to the presence of aglycones (anthocyanidins) (De Rosso et al., 2008), which are less stable than the corresponding glycosylated anthocyanins ( $\mathrm{He}$ and Giusti, 2010).

Some inorganic compounds have been reported to change color and enhance color stability of anthocyanins. Flavylium derivatives and an anthocyanin were demonstrated to present enhanced color stability when in solution with clay minerals like montmorillonite (Mt) (Kohno et al., 2007; Kohno et al., 2009), which was ascribed to electrostatic host-guest interaction and steric protection resulting from the intercalation of anthocyanins into Mt interlayers by cation exchange. Unmodified Mt has been reported as non-toxic to human intestinal cell line Caco-2 (Maisanaba et al., 2014), and has been considered as safe to be added to human diets to decrease the bioavailability of aflatoxins (Wang et al., 2007).

In a previous study from this group (Ribeiro et al., 2018), Mt was

\footnotetext{
* Corresponding author at: Embrapa Instrumentação, R. 15 de Novembro 1452, 13560-970 São Carlos, SP, Brazil.

E-mail addresses: edy.brito@embrapa.br (E.S. Brito), men.souza@embrapa.br (M.d.s.M. Souza Filho), henriette.azeredo@embrapa.br (H.M.C. Azeredo).
} 
demonstrated to intercalate anthocyanins from clarified acerola juice, which resulted in a dramatic color change (from yellowish to bright red) and color stabilization of the juice. The objective of the present study was to evaluate the effectiveness of Mt to act as both color stabilizer and reinforcing phase to gelatin films containing clarified acerola juice.

\section{Materials and methods}

\subsection{Preparation of clarified acerola juice}

Frozen acerola puree (Pomar da Polpa, Fortaleza, Brazil) was thawed at $4{ }^{\circ} \mathrm{C}$ in a refrigeration chamber, homogenized in an UltraTurrax T50 (Ika Labortechnik, Staufen, Germany) at $8000 \mathrm{rpm}$ for $10 \mathrm{~min}$, and centrifuged at 26,400 $\mathrm{g}$ (Hitachi CR22GIII, Hitachi Koki Co., Japan) for $30 \mathrm{~min}$ at $20^{\circ} \mathrm{C}$. The supernatant was vacuum filtered through a $28 \mu \mathrm{m}$ filter paper, resulting in clarified acerola juice.

\subsection{Preparation of gelatin films}

Each film was prepared from $25 \mathrm{~g}$ bovine gelatin powder (Bloom value 226, PB Leiner, Acorizal, Brazil), $250 \mathrm{~mL}$ clarified acerola juice (with $6.5 \mathrm{wt} \%$ solids), 12.5 g glucose syrup with $80 \%$ glucose (Du Porto, Porto Feliz, Brazil) as a film plasticizer and sweetener, and Mt (Proenol CN45, Flow Chemical, São Paulo, Brazil, an aluminum silicate containing the following chemical composition, as informed by the manufacturer: $\mathrm{SiO}_{2}, 66.0 \% ; \mathrm{Fe}_{2} \mathrm{O}_{3}, 3.0 \%$; $\mathrm{CaO}, 1.0 \% ; \mathrm{TiO}_{2}, 0.8 \% ; \mathrm{Al}_{2} \mathrm{O}_{3}$, $19.5 \% ; \mathrm{MgO}, 5.0 \% ; \mathrm{Na}_{2} \mathrm{O}, 3.0 \% ; \mathrm{K}_{2} \mathrm{O}, 0.1 \%$ ). The following Mt contents were defined for the films: $0,2,4,6,8$, and $10 \mathrm{wt} \%$ when based on dry acerola juice, which turned out to be $0,1.3,2.6,3.9,5.2$, and $6.5 \mathrm{wt} \%$ respectively, when based on the gelatin matrix.

Mt was firstly hydrated in clarified acerola juice under stirring $(660 \mathrm{rpm})$ for $30 \mathrm{~min}$, then sonicated in an ultrasonic cell disruptor (DES500, Unique Group, Indaiatuba, Brazil) at a frequency of $20 \mathrm{kHz}$ for two 5 min cycles at $500 \mathrm{~W}$ with a $5 \mathrm{~min}$ interval in between. The gelatin was then added, and the mixture was stirred $(660 \mathrm{rpm})$ for $30 \mathrm{~min}$ at $25^{\circ} \mathrm{C}$, then for more $30 \mathrm{~min}$ at $50^{\circ} \mathrm{C}$. The glucose syrup was then added, and the dispersion was stirred $(660 \mathrm{rpm})$ for $30 \mathrm{~min}$, homogeneized in an Ultra-Turrax T-25 (Ika, Staufen, Germany) at $10000 \mathrm{rpm}$ for $15 \mathrm{~min}$, sonicated $(20 \mathrm{kHz}, 500 \mathrm{~W}, 5 \mathrm{~min})$, and degassed with a vacuum pump (DVP RC.8D, Vacuum Technology, Italy) to remove bubbles. The dispersion was then cast on Mylar ${ }^{\circledR}$ films fixed on $30 \times 30 \mathrm{~cm}$ glass plates, leveled with a draw-down bar to a final dry thickness of $0.08 \mathrm{~mm}$, and left to dry at $24^{\circ} \mathrm{C}$ for $24 \mathrm{~h}$. Dried samples were cut and detached from the Mylar surface.

\subsection{Determinations on gelatin films}

\subsubsection{Tensile tests}

At least ten $125 \times 12.5 \mathrm{~mm}$ film strips were conditioned for $48 \mathrm{~h}$ under controlled humidity $\left(50 \pm 5{ }^{\circ} \mathrm{C}\right)$ and temperature $\left(23 \pm 1{ }^{\circ} \mathrm{C}\right)$ and had their thicknesses measured with an Akrom KR1250 coating thickness tester (Akrom, São Leopoldo, RS, Brazil) to the nearest $1 \mu \mathrm{m}$ at 7-8 random locations. The strips had their tensile properties measured according to the D882-12 method (ASTM, 2012), using an Emic DL-3000 Universal Testing Machine (Emic, São José dos Pinhais, Brazil) with a load cell of $100 \mathrm{~N}$, initial grip separation of $100 \mathrm{~mm}$, and crosshead speed of $12.5 \mathrm{~mm} \cdot \mathrm{min}^{-1}$.

\subsubsection{Water vapor permeability (WVP)}

Six circular $(30 \mathrm{~mm}$ in diameter) film samples, previously conditioned ( $48 \mathrm{~h}, 50 \pm 5{ }^{\circ} \mathrm{C}, 23 \pm 1{ }^{\circ} \mathrm{C}$ ) and with their thicknesses measured at 7-8 random locations, were submitted to water vapor permeability (WVP) determination according to the E96-05 method (ASTM, 2016). The film samples were sealed as patches onto acrylic permeation cells (24 mm in diameter and $10 \mathrm{~mm}$ in height) containing $2 \mathrm{~mL}$ distilled water. The test was carried out at $24^{\circ} \mathrm{C}$, using silica gel in the desiccator (outside the permeation cells). Eight measurements were taken within $24 \mathrm{~h}$.

\subsubsection{Opacity}

Film opacity determination (in triplicate) was based on a method described by Irissin-Mangata et al. (2001). Films were cut into rectangular $(10 \times 50 \mathrm{~mm})$ strips and placed on the internal side of a UV-visible spectrophotometer cell (perpendicularly to the light beam), and the absorbance spectrum $(400-800 \mathrm{~nm})$ of film samples was recorded on a Shimadzu UV-2450 spectrometer (Shimadzu, Japan) equipped with an integrating sphere (ISR-2200, Shimadzu, Japan). Flm opacity was defined as the area under the recorded curve (estimated by the linear trapezoidal rule) and expressed as absorbance units $\times$ nanometers (wavelength)/millimeters (film thickness) (A.nm.mm ${ }^{-1}$ ).

\subsubsection{Color parameters and stability}

Film forming dispersions for color analyses were prepared as described previously (item 2.2$)$, except that $0.1 \%(w / v)$ potassium sorbate was added in order to avoid microbial growth ${ }^{1}$ (which might change the material color). $25 \mathrm{~mL}$ of each dispersion were cast on a $90-\mathrm{mm}$ petri dish. The following color parameters of the films were measured: lightness ( $\mathrm{L}^{*}$, ranging from 0 to 100 , representing black and white, respectively), red-green chromaticity (a*, negative values indicating green and positive values indicating magenta), and yellow-blue chromaticity $\left(b^{*}\right.$, negative values indicating blue and positive values indicating yellow). Color measurements were carried out with a Konica-Minolta CR-400 colorimeter (Minolta, Colombes, France) standardized with a white reference plate $\left(\mathrm{L}^{*}=95.62, \mathrm{a}^{*}=-0.22\right.$ and $\mathrm{b}^{*}=2.45$ ). Measurements were taken (as the average of five points of each sample) daily for the first 8 days of storage at $24^{\circ} \mathrm{C}$, and another measurement was taken at 18 days of storage. Total color differences $\left(\Delta \mathrm{E}^{*}\right)$ were calculated according to Eq. 1 , to assess the color variation throughout storage time.

$\Delta E *\left[(\Delta L)^{2}+(\Delta a)^{2}+(\Delta b)^{2}\right]^{1 / 2}$

where $\Delta \mathrm{L}^{*}, \Delta \mathrm{a}^{*}$, and $\Delta \mathrm{b}^{*}$ are the differences in $\mathrm{L}^{*}, \mathrm{a}^{*}$, and $\mathrm{b}^{*}$ values after 17 days of storage when compared to the beginning of storage (day 0).

\subsection{5. $X$-ray diffraction}

$\mathrm{X}$-ray diffraction (XRD) was used to assess the interlayer $d$-spacing of (001) plane of Mt, i.e. the distance between its basal layers (Morgan and Gilman, 2003), in order to indirectly evaluate the capacity of Mt of intercalating film components.

The X-ray powder diffraction experiments were performed for films containing $0,3.9$, and $6.5 \mathrm{wt} \% \mathrm{Mt}$ (on a gelatin basis) in a Rigaku diffractometer (DMAXB) with a $\mathrm{Cu} \mathrm{K} \alpha(\lambda=0.154 \mathrm{~nm})$ radiation tube operated at $40 \mathrm{kV} / 25 \mathrm{~mA}$. The diffractions were taken in the $3-35^{\circ}(2 \theta)$ range in step sizes of $0.02^{\circ}$, and scan speed of $0.25^{\circ} \cdot \mathrm{min}^{-1}$. The $d$ spacing was calculated from Bragg's law (Eq. (2)).

$d=\frac{\lambda}{2 \sin \theta}$

where $\lambda$ is the radiation wavelength $(0.154 \mathrm{~nm})$, and $2 \theta$ is the position of the (001) peak in the XRD pattern.

\subsubsection{Fourier Transform Infrared (FTIR) spectra}

The FTIR spectra of films and pure Mt were recorded with a Perkin

\footnotetext{
${ }^{1}$ Microbial growth was a concern for this specific analysis, since a $0.4 \mathrm{~mm}$ thick layer was to be obtained (much higher than the $0.08 \mathrm{~mm}$ for films) in order to minimize color interferences from the bottom (reference plate), and it took much longer $(72 \mathrm{~h})$ for this layer to dry when compared to the regular films (24 h).
} 
Elmer (FTIR/NIR Frontier, Perkin Elmer, Waltham, MA, USA) equipped with a MIRacle ATR accessory (Pike Technologies, Madison, WI, USA) with a ZnSe reflection crystal, in the range of $4000-550 \mathrm{~cm}^{-1}$.

\subsubsection{Scanning electron microscopy (SEM)}

The micrographs of the films were taken using a scanning electron microscope (TESCAN VEGA/XMU, Brno, Czech Republic). Samples for surface imaging were mounted on aluminum stubs using carbon-coated double sided adhesive tape and coated with gold using an Emitech K550 sputtering coater. Other specimens were immersed in liquid nitrogen, fractured, and mounted on aluminum stubs with adhesive tape and gold-coated for observation of the fractured surfaces. The samples were examined using an accelerating voltage of $15 \mathrm{kV}$, at $2,670 \times$ magnification for top (air) surfaces and 1,330 $\times$ for fractured surfaces.

\section{Results and discussion}

\subsection{Tensile properties, WVP, and opacity}

The Mt addition was effective to increase the tensile strength and elastic modulus of the gelatin-acerola juice films, while decreasing elongation (Fig. 1), as expected from previous studies on Mt-filled films (Flaker et al., 2015; Romero-Bastida et al., 2015; Oliveira et al., 2016). Mt contents of $3.9 \mathrm{wt} \%$ or more provided the films with strength values at least $18 \%$ higher than the one of the unfilled film, whereas the modulus was significantly increased by Mt contents as low as $2.6 \mathrm{wt} \%$ Mt, without further increasing with higher Mt contents. The elongation was reduced in about $30 \%$ when $6.5 \mathrm{wt} \%$ Mt was added. Although higher Mt concentrations could promote even higher tensile strength and modulus values, it would probably result in too low elongations, as reported by Romero-Bastida et al. (2015). Actually, $7 \mathrm{wt} \%$ Mt was reported by Flaker et al. (2015) to be an Mt concentration high enough to dramatically reduce the tensile strength in gelatin films. While this may seem inconsistent with the findings of this study, which demonstrated $6.5 \mathrm{wt} \%$ Mt to be not high enough to show any impairments on tensile strength, it is important to point out that the films in this study had also (besides gelatin) solids from acerola juice, so the actual Mt contents of the films were lower than the labeled values.

Although the behavior of WVP as a function of Mt contents seems a bit inconsistent, it tended to decrease with increasing Mt contents (Fig. 1), mainly when considering that the film with $6.5 \mathrm{wt} \%$ Mt presented a WVP which was $45 \%$ lower than that of the film with no Mt. This decreasing effect of Mt on WVP of films has been observed in other studies (Romero-Bastida et al., 2015; Oliveira et al., 2016), and is ascribed to the so-called tortuous path effect, i.e. an increased diffusion path length for permeants such as water vapor through the matrix due to obstacles created by the presence of impervious particles (Tan and Thomas, 2017; Monteiro et al., 2018).

The films lost transparency with Mt addition, corroborating previous studies on Mt effects on films (Pinto et al., 2015; Martucci and Ruseckaite, 2010). The increased opacity was especially remarkable at the highest Mt content (6.5 wt\%), and is ascribed to change in light diffraction by the dispersed Mt (Slavutsky et al., 2014) and/or to some Mt aggregation.

\subsection{Color stability of films}

The film without Mt addition was pale (yellowish) since the beginning of storage, and suffered noticeable color changes with time (Fig. 2), with increasing $a^{*}$ and $b^{*}$ values and decreasing $L^{*}$. On the other hand, the color of the films containing Mt were more intense (redder) and more stable with storage time, similarly to the alginateacerola puree coating added with Mt as described previously (Azeredo
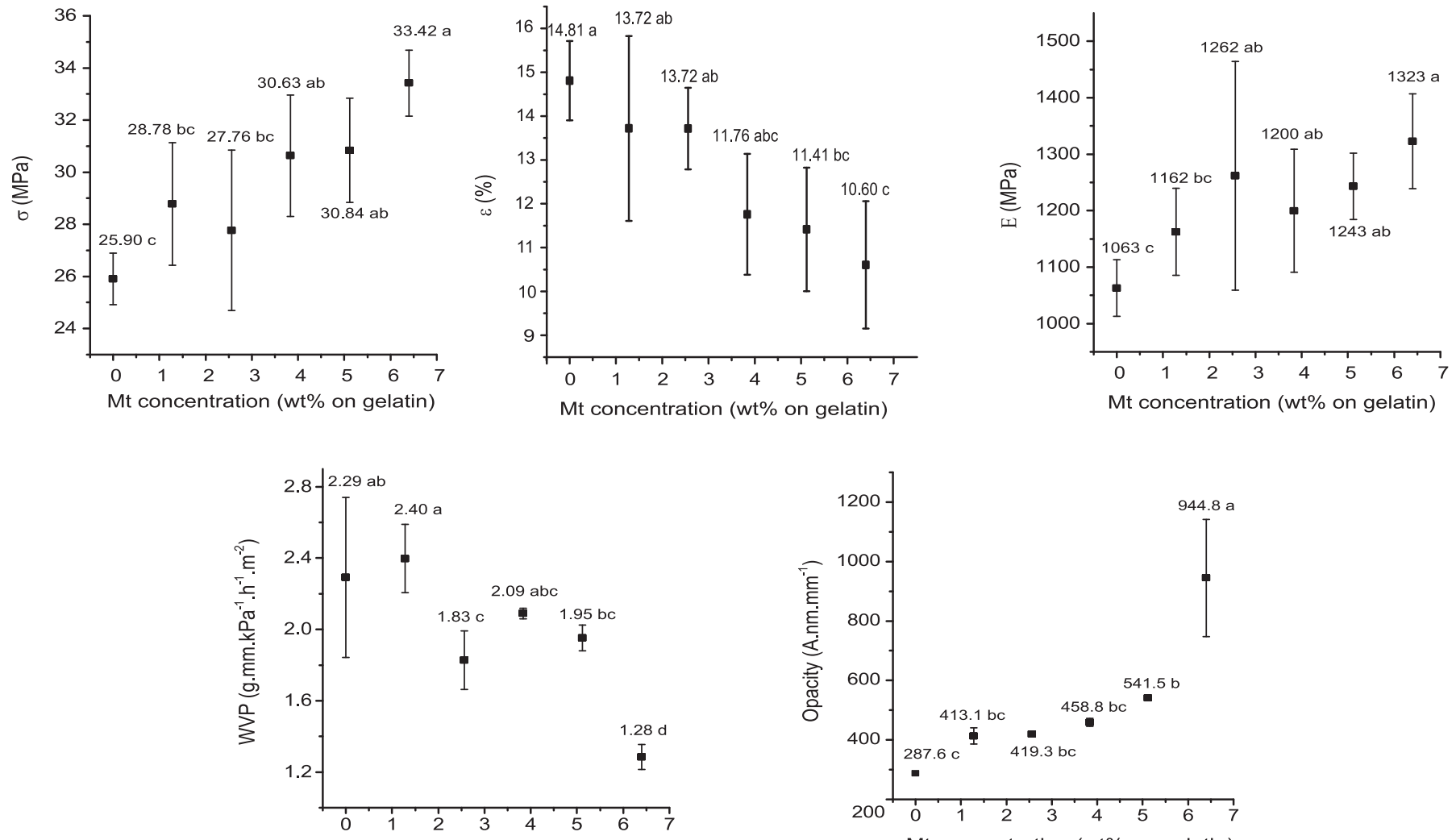

Mt concentration (wt \% on gelatin)

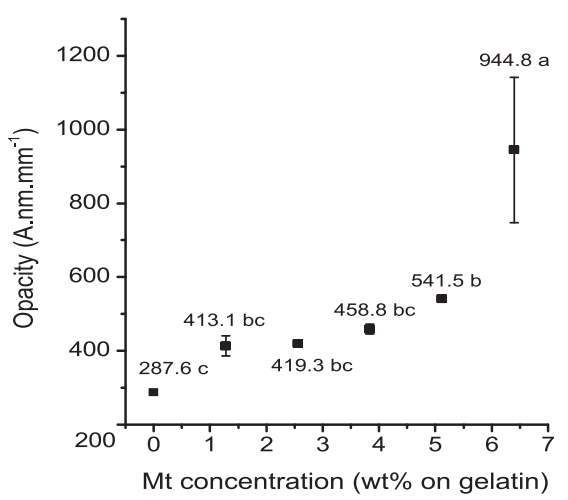

Fig. 1. Tensile, barrier, and optical properties of films with different Mt contents. $\sigma$ : tensile strength; $\varepsilon$ : elongation at break; E: elastic modulus; WVP: water vapor permeability. For each property, values sharing a common letter are not significantly different $(p>0.05)$. 

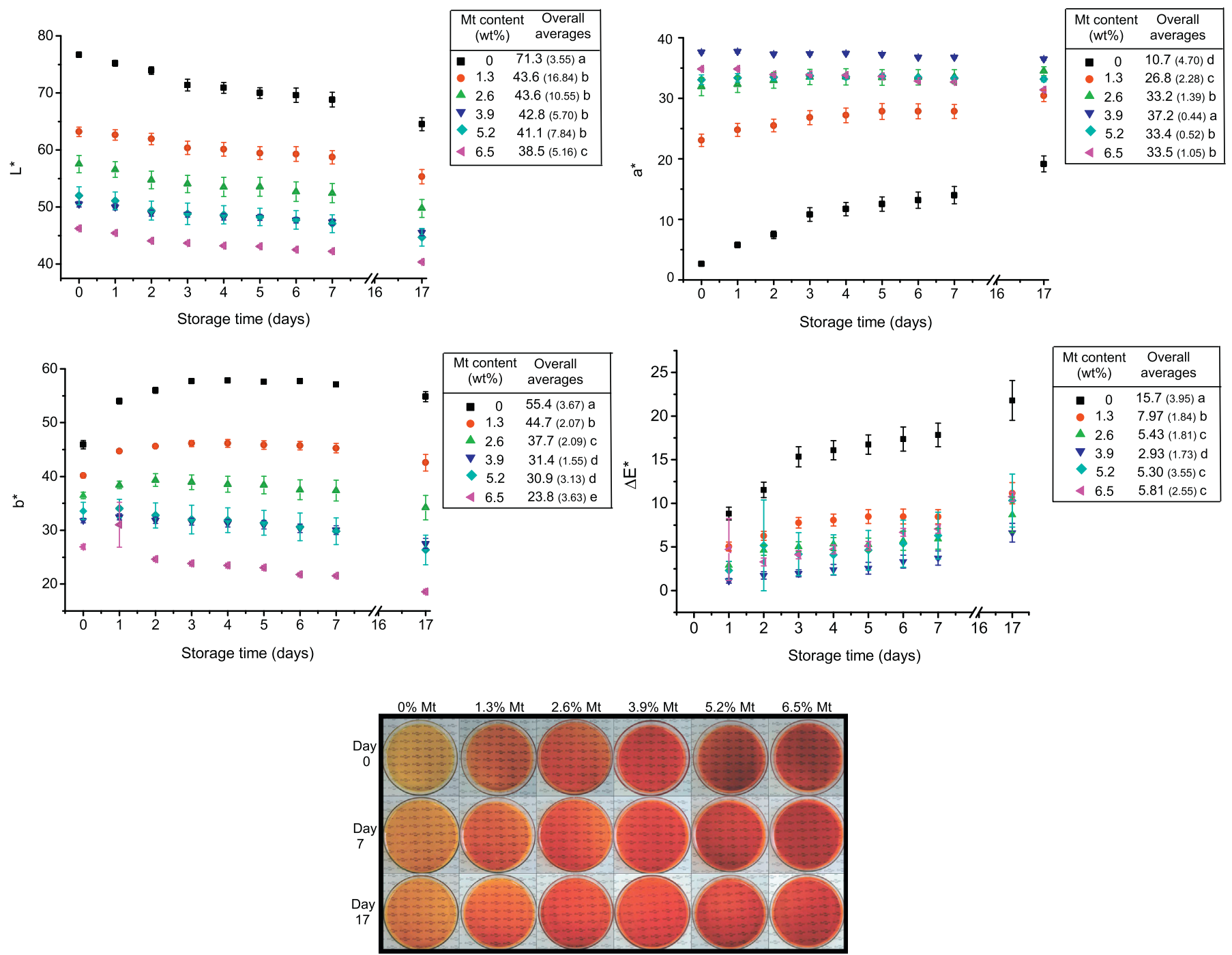

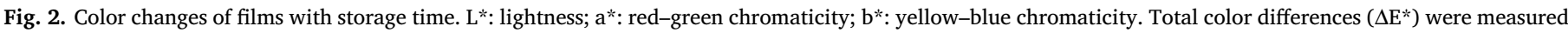

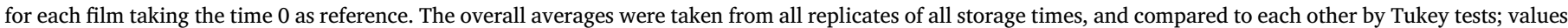

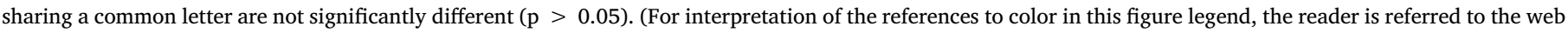
version of this article.)

et al., 2012b). The total color differences ( $\Delta \mathrm{E}^{*}$ ) of all films with Mt were significantly lower than the one of the unfilled film. The lowest $\Delta \mathrm{E}^{*}$ value was presented by the film with $3.9 \mathrm{wt} \% \mathrm{Mt}$, and higher Mt concentrations resulted in increased $\Delta \mathrm{E}^{*}$ values, probably due to some Mt aggregation, which may have impaired Mt-anthocyanin interactions. The color shift (to redder shades) of the films with Mt may be ascribed to electrostatic host-guest interaction (Kohno et al., 2007, 2009) and/or the formation of aggregates of anthocyanin molecules near Mt platelets (Gavara et al., 2013; Kohno et al., 2015), while some steric protection by Mt (Kohno et al., 2007, 2009) may have also contributed to the color stability of the films throughout storage.

\subsection{FTIR spectra}

The FTIR spectra of films (with and without Mt) and pure Mt were presented at Fig. 3. Mt presented characteristic bands of in-plane and out-of-plane $\mathrm{Si}-\mathrm{O}$ stretching at $1045 \mathrm{~cm}^{-1}$ and $1117 \mathrm{~cm}^{-1}$ respectively (Madejová, 2003; Patel et al., 2007), as well as the one at about $1637 \mathrm{~cm}^{-1}$, ascribed to $\mathrm{H}-\mathrm{O}-\mathrm{H}$ bending of water (Xie et al., 2001; Madejová, 2003). Both films (with or without Mt) exhibited typical gelatin bands such as that of $\mathrm{C}=\mathrm{O}$ stretching (amide I) at $1635 \mathrm{~cm}^{-1}$ (Kittiphattanabawon et al., 2016), amide II (in-plane $\mathrm{N}-\mathrm{H}$ bending) at
$1550 \mathrm{~cm}^{-1}$, amide III (C-N stretching) at $1239 \mathrm{~cm}^{-1}$ and $1203 \mathrm{~cm}^{-1}$ (Kaewruang et al., 2014), $\mathrm{CH}_{2}$ asymmetric bending at $1449 \mathrm{~cm}^{-1}$ (Jackson et al., 1995), C-N stretching vibrations of primary amides at $1405 \mathrm{~cm}^{-1}$ (Li et al., 2017), $\mathrm{CH}_{2}$ wagging of proline side chains at $1337 \mathrm{~cm}^{-1}$ (Jackson et al., 1995), and C-O stretching at $1077-1148 \mathrm{~cm}^{-1}$ (Jackson et al., 1995; Tseng et al., 2009).

No evidence has been found from FTIR spectra to support complexation of anthocyanins with Mt, although a possible band at about $1536 \mathrm{~cm}^{-1}$ could have been masked by the one at $1550 \mathrm{~cm}^{-1}$. Such a band, not evident in this study but reported in our previous study with Mt-added acerola juice (Ribeiro et al., 2018), is ascribed to complexation of anthocyanins with metals such as iron (Buchweitz et al., 2012). Since the color instability of anthocyanins at weakly acid to neutral $\mathrm{pH}$ is ascribed to the hydration of flavylium cation producing the colorless pseudobase, complexation has been demonstrated to improve the pigment stability (Fedenko et al., 2017; Yoshida et al., 2009). Trivalent metal ions have been demonstrated to be especially effective to complex to anthocyanins, due to their higher electron density when compared to divalent cations (Sigurdson et al., 2016). Apart from $\mathrm{Fe}^{3+}$ ions (Sigurdson et al., 2016; Tachibana et al., 2014), anthocyanins have also been reported to form color stabilized coordinated complexes to $\mathrm{Al}^{3+}$ (Fedenko et al., 2017; Oyama et al., 2015; Sigurdson et al., 2016), also 


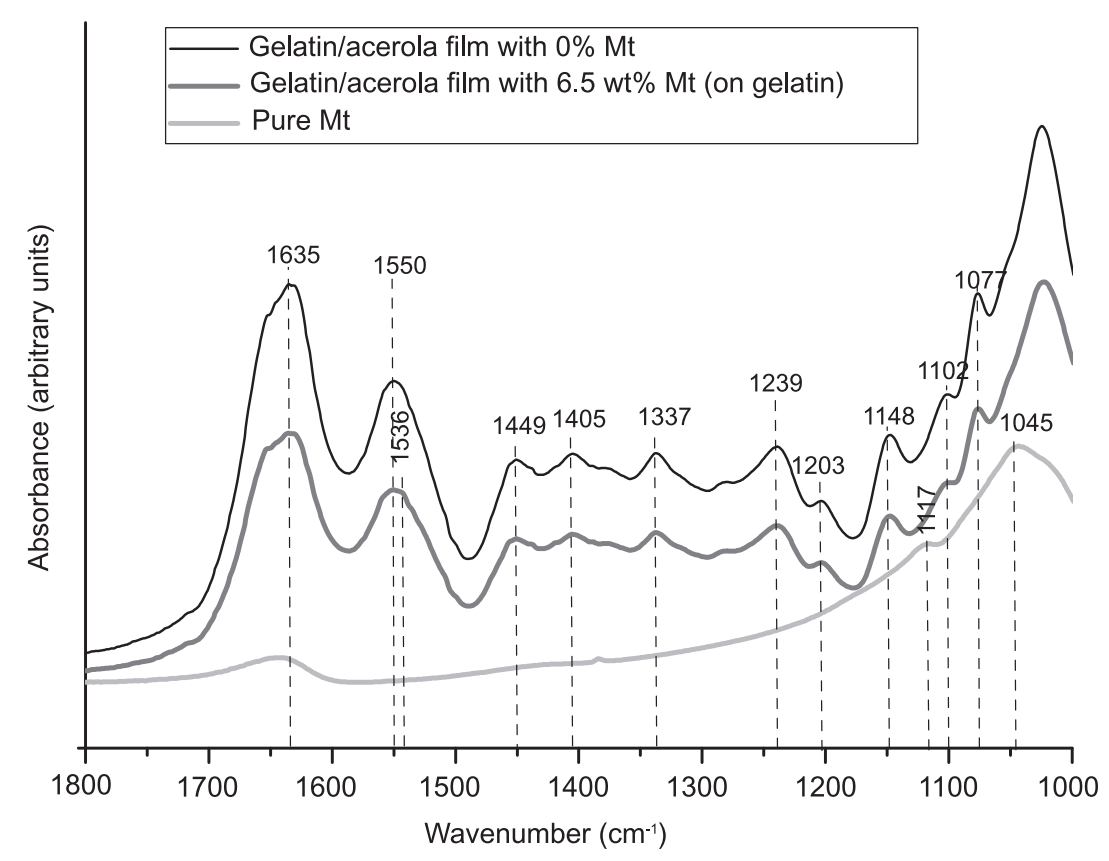

Fig. 3. FTIR spectra of films and Mt.

present in Mt.

\subsection{X-ray diffractograms (XRD)}

The diffractogram of pristine Mt (Fig. 4) revealed a characteristic peak of (001) plane at $2 \theta=7.14^{\circ}$, which, according to Bragg's law, corresponds to an interlayer space $\left(\mathrm{d}_{001}\right)$ of $1.24 \mathrm{~nm}$, corroborating previous reports (Echeverria et al., 2014; Martucci and Ruseckaite, 2010). On the other hand, the XRD patterns of composite films were more similar to that of the unfilled gelatin/CAJ film, not exhibiting the (001) peak. Whereas intercalated composites (in which the platelets keep an ordered configuration) are characterized by increased basal spacing when compared to pristine Mt (the diffraction peak shifting to lower angles), the absence of diffraction peaks (as in this study) suggests the formation of exfoliated composites, in which the platelets were separated (Zheng et al., 2002; Mahmoudian et al., 2012; Mu et al., 2013), although it is not possible to affirm exfoliation without proper

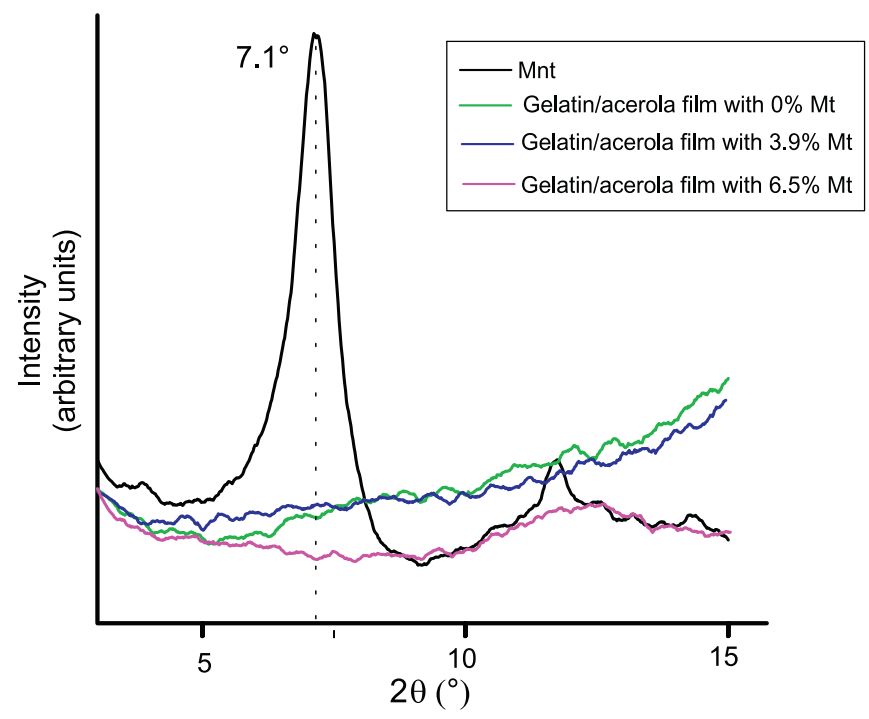

Fig. 4. X-ray diffractograms of films and Mt. $2 \Theta$ : scattering angles. transmission electron micrographs, which were not carried out. So, it is supposed that the anthocyanins were immobilized on the external surface of the Mt, as suggested by Ogawa et al. (2017), or that metals such as $\mathrm{Fe}^{3+}$, and $\mathrm{Al}^{3+}$ have formed complexes to anthocyanins (Fedenko et al., 2017; Oyama et al., 2015; Sigurdson et al., 2016), or even promoted stacking or self-association of anthocyanins (Schreiber et al., 2010).

\subsection{Scanning electron microscopy (SEM)}

All films (even the one without Mt) presented heterogeneous surfaces (Fig. 5), ascribed to the presence of fruit components. Since the density of dark spots in the film surfaces decreased with the addition of $\mathrm{Mt}$, it is probable that the dark spots have been constituted by compounds that were complexed to Mt (such as anthocyanins). Heterogeneous surfaces were also observed from pectin films containing açai puree (Espitia et al., 2014). The fractured cross-section of the film without Mt was relatively smooth, whereas the film with $3.9 \mathrm{wt} \% \mathrm{Mt}$ showed an ordered laminated structure. The fractured cross-section became rougher and exhibiting cracks when the Mt content increased to $6.5 \mathrm{wt} \%$, which may be ascribed to aggregates of Mt (either complexed or not to anthocyanins), and was reflected by a decreased elongation (Fig. 1), although those discontinuities have not impaired the other tensile properties of the films.

\section{Conclusions}

Montmorillonite (Mt) has been added in different concentrations to gelatin films containing acerola juice. Mt not only acted as a reinforcing agent, enhancing tensile strength and modulus, and reducing the water vapor permeability, but also interacted with the acerola anthocyanins (as corroborated by FTIR), changing the film color from yellowish (indicating previous degradation of anthocyanins upon processing and/ or storage) to red. Moreover, it promoted color stabilization throughout storage, mainly when added at $3.9 \%$. The color changes and stabilization may be due to the formation of metal complexes to anthocyanins. The acerola juice containing films could be used for applications in which fruit flavor and color are desirable, such as fruit wraps and fruit ribbons. 
(A1)

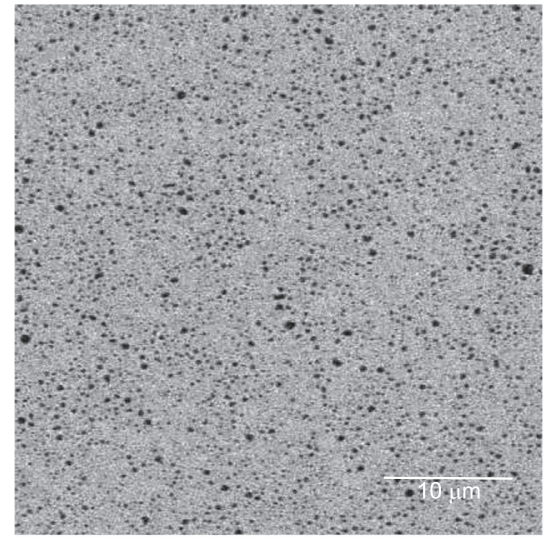

(A2)

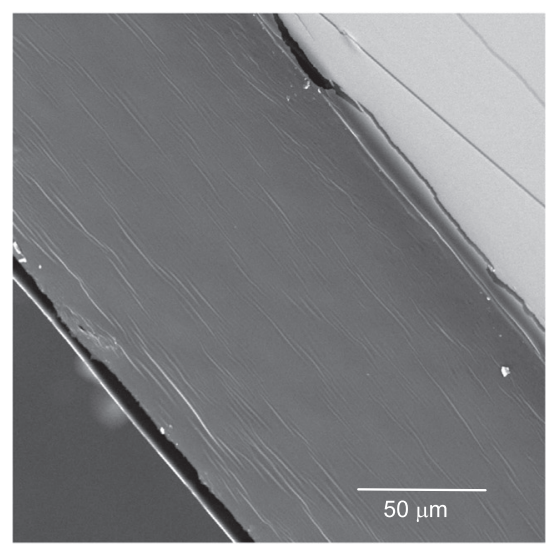

(B1)

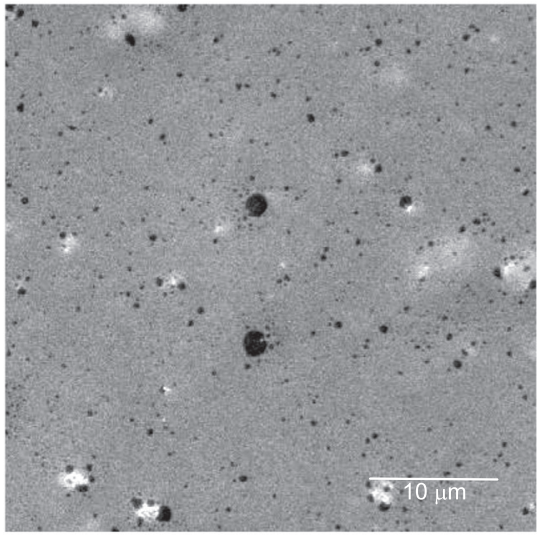

(B2)

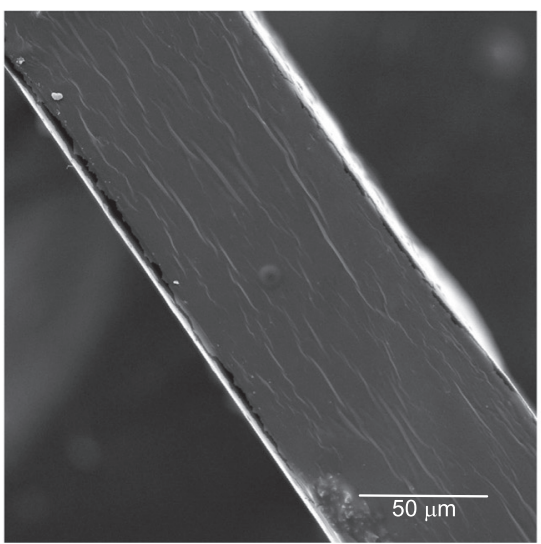

(C1)

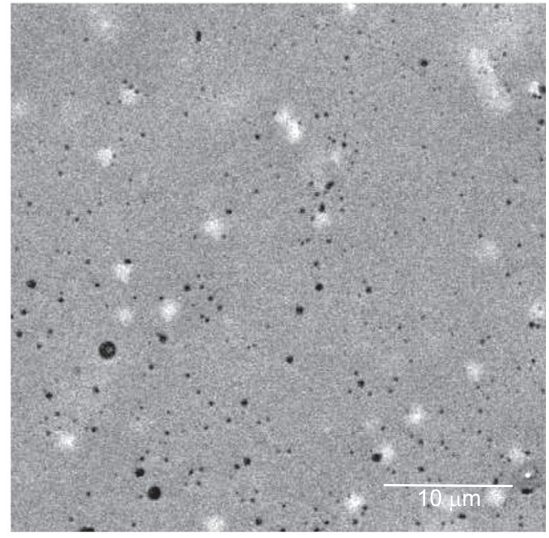

(C2)

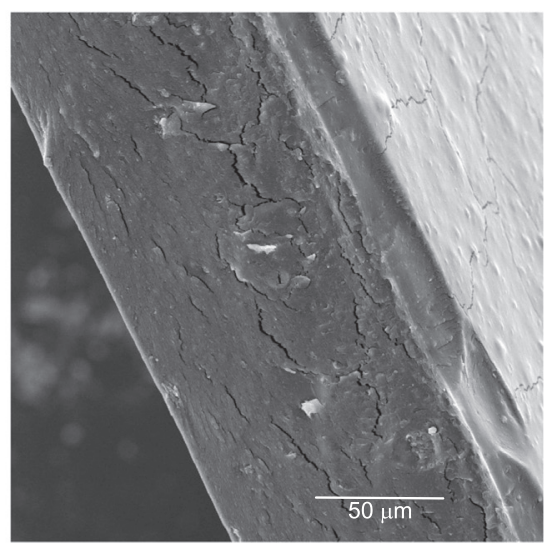

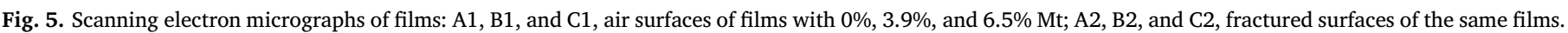

\section{Acknowledgements}

The authors gratefully acknowledge the financial support of the National Collaborative Research Network in Nanotechnology Applied to Agribusiness (AgroNano, Embrapa, Brazil, 0114030010300) and the National Council for Scientific and Technological Development (CNPq, Brazil, INCT-Frutos Tropicais, 465335/2014-4). They also thank Flow Chemical Ltd. for providing them with Mt, and Celli Rodrigues Muniz (Embrapa Agroindústria Tropical) for her help with the SEM micrographs. Author Ribeiro thanks the Coordination for the Improvement of Higher Education Personnel (CAPES) for his MSc scholarship (1708268). Authors Brito and Azeredo thank CNPq for their Research Productivity Fellowships (302770/2015-1 and 302381/2016-3 respectively).

\section{References}

ASTM D882-12, 2012. Standard Test Method for Tensile Properties of Thin Plastic Sheeting. ASTM International, West Conshohocken.

ASTM E96/E96M-16, 2016. Standard Test Methods for Water Vapor Transmission of Materials. ASTM International, West Conshohocken.

Azeredo, H.M.C., Miranda, K.W.E., Rosa, M.F., Nascimento, D.M., De Moura, M.R., 2012a. Edible films from alginate-acerola puree reinforced with cellulose whiskers. LWT Food Sci. Technol. 46, 294-297.

Azeredo, H.M.C., Miranda, K.W.E., Ribeiro, H.L., Rosa, M.F., Nascimento, D.M., 2012b. Nanoreinforced alginate-acerola puree coatings on acerola fruits. J. Food Eng. 113 505-510.

Azeredo, H.M.C., Morrugares-Carmona, R., Wellner, N., Cross, K., Bajka, B., Waldron, K.W., 2016. Development of pectin films with pomegranate juice and citric acid. Food Chem. 198, 101-106.

Brito, E.S., Araújo, M.C.P., Alves, R.E., Carkeet, C., Clevidence, B.A., Novotny, J.A., 2007. Anthocyanins present in selected tropical fruits: acerola, jambolão, Jussara, and guajiru. J. Agric. Food Chem. 55, 9389-9394.
Buchweitz, M., Gudi, G., Carle, R., Kammerer, D.R., Schulz, H., 2012. Systematic investigations of anthocyanin-metal interactions by Raman spectroscopy. J. Raman Spectrosc. 43, 2001-2007.

De Rosso, V.V., Mercadante, A.Z., 2007. The high ascorbic acid content is the main cause of the low stability of anthocyanin extracts from acerola. Food Chem. 103, 935-943.

De Rosso, V.V., Hillebrand, S., Montilla, E.C., Bobbio, F.O., Winterhalter, P., Mercadante, A.Z., 2008. Determination of anthocyanins from acerola (Malpighia emarginata DC.) and açaí (Euterpe oleracea Mart.) by HPLC-PDA-MS/MS. J. Food Compos. Anal. 21, 291-299.

Echeverria, I., Eisenberg, P., Mauri, A.N., 2014. Nanocomposites films based on soy proteins and montmorillonite processed by casting. J. Membr. Sci. 449, 15-26.

Espitia, P.J., Avena-Bustillos, R.J., Du, W.-X., Teófilo, R.F., Soares, N.F.F., McHugh, T.H., 2014. Optimal antimicrobial formulation and physical-mechanical properties of ed ible films based on açaí and pectin for food preservation. Food Pack. Shelf Life 2, 38-49.

Fedenko, V.S., Shemet, S.A., Landi, M., 2017. UV-vis spectroscopy and colorimetric models for detecting anthocyanin-metal complexes in plants: an overview of in vitro and in vivo techniques. J. Plant Physiol. 212, 13-28.

Flaker, C.H.C., Lourenço, R.V., Bittante, A.M.Q.B., Sobral, P.J.A., 2015. Gelatin-based nanocomposite films: a study on montmorillonite dispersion methods and concentration. J. Food Eng. 167, 65-70.

Gavara, R., Petrov, V., Quintas, A., Pina, F., 2013. Circular dichroism of anthocyanidin 3glucoside self-aggregates. Phytochemistry 88, 92-98.

Guldiken, B., Gibis, M., Boyacioglu, D., Capanoglu, E., Weiss, J., 2017. Impact of liposomal encapsulation on degradation of anthocyanins of black carrot extract by adding ascorbic acid. Food Funct. 2017, 1085-1093.

He, J., Giusti, M.M., 2010. Anthocyanins: natural colorants with health-promoting properties. Annu. Rev. Food Sci. Technol. 1, 163-187.

Irissin-Mangata, J., Bauduin, G., Boutevin, B., Gontard, N., 2001. New plasticizers for wheat gluten films. Eur. Polym. J. 37, 1533-1541.

Jackson, M., Choo, L.P., Watson, P.H., Halliday, W.C., Mantsch, H.H., 1995. Beware of connective tissue proteins: assignment and implications of collagen absorptions in infrared spectra of human tissues. Biochim. Biophys. Acta 1270, 1-6.

Kaewruang, P., Benjakul, S., Prodpran, T., 2014. Effect of phosphorylation on gel properties of gelatin from the skin of unicorn leatherjacket. Food Hydrocoll. 35, 694-699. Kittiphattanabawon, P., Benjakul, S., Sinthusamran, S., Kishimura, H., 2016. Gelatin from clown featherback skin: extraction conditions. LWT Food Sci. Technol. 66, 186-192.

Kohno, Y., Hoshino, R., Matsushima, R., Tomita, Y., Kobayashi, K., 2007. Stabilization of 
flavylium dyes by incorporation in the clay interlayer. J. Jpn Soc. Colour Mater. 80, $6-12$.

Kohno, Y., Kinoshita, R., Ikoma, S., Yoda, K., Shibata, M., Matsushima, R., Tomita, Y., Maeda, Y., Kobayashi, K., 2009. Stabilization of natural anthocyanin by intercalation into montmorillonite. Appl. Clay Sci. 42, 519-523.

Kohno, Y., Kato, Y., Shibata, M., Fukuhara, C., Maeda, Y., Tomita, Y., Kobayashi, K., 2015. Enhanced stability of natural anthocyanin incorporated in Fe-containing mesoporous silica. Microporous Mesoporous Mater. 203, 232-237.

Li, G., Nandgaonkar, A.G., Habibi, Y., Krause, W.E., Wei, Q., Lucia, L.A., 2017. An environmentally benign approach to achieving vectorial alignment and high microporosity in bacterial cellulose/chitosan scaffolds. RSC Adv. 7, 13678-13688.

Madejová, J., 2003. FTIR techniques in clay mineral studies. Vib. Spectrosc. 31, 1-10.

Mahmoudian, S., Wahit, M.U., Ismail, A.F., Yussuf, A.A., 2012. Preparation of regenerated cellulose/montmorillonite nanocomposite films via ionic liquids. Carbohydr. Polym. $88,1251-1257$.

Maisanaba, S., Gutiérrez-Praena, D., Pichardo, S., Moreno, F.J., Jordá, M., Carmeán, A.M., Aucejo, S., Jos, A., 2014. Toxic effects of a modified montmorillonite clay on the human intestinal cell line Caco-2. J. Appl. Toxicol. 34, 714-725.

Martucci, J.F., Ruseckaite, R.A., 2010. Biodegradable bovine gelatin/ $\mathrm{Na}^{+}$-montmorillonite nanocomposite films. Structure, barrier and dynamic mechanical properties. Polym.-Plast. Technol. Eng. 49, 581-588.

McGhie, T.K., Walton, M.C., 2007. The bioavailability and absorption of anthocyanins: towards a better understanding. Mol. Nutr. Food Res. 51, 702-713.

Mercali, G.D., Jaeschke, D.P., Tessaro, I.C., Marczak, L.D.F., 2013. Degradation kinetics of anthocyanins in acerola pulp: comparison between ohmic and conventional heat treatment. Food Chem. 136, 853-857.

Mercali, G.D., Schwartz, S., Marczak, L.D.F., Tessaro, I.C., Sastry, S., 2014. Ascorbic acid degradation and color changes in acerola pulp during ohmic heating: effect of electric field frequency. J. Food Eng. 123, 1-7.

Monteiro, M.K.S., Oliveira, V.R.L., Santos, F.K.G., Barros Neto, E.L., Leite, R.H.L., Aroucha, E.M.M., Silva, R.R., Silva, K.N.O., 2018. Incorporation of bentonite clay in cassava starch films for the reduction of water vapor permeability. Food Res. Int. 105, 637-644.

Morgan, A.B., Gilman, J.W., 2003. Characterization of polymer-layered silicate (clay) nanocomposites by transmission electron microscopy and X-ray diffraction: a comparative study. J. Appl. Polym. Sci. 87, 1329-1338.

Mu, C., Li, X., Zhao, Y., Zhang, H., Wang, L., Li, D., 2013. Freezing/thawing effects on the exfoliation of montmorillonite ingelatin-based bionanocomposite. J. Appl. Polym. Sci. 2013, 3141-3148.

Ogawa, M., Takee, R., Okabe, Y., Seki, Y., 2017. Bio-geo hybrid pigment; clay-anthocyanin complex which changes color depending on the atmosphere. Dyes Pigments 139, 561-565.

Oliveira, T.I.S., Zea-Redondo, L., Moates, G.K., Wellner, N., Cross, K., Waldron, K.W., Azeredo, H.M.C., 2016. Pomegranate peel pectin films as affected by montmorillonite. Food Chem. 198, 107-112.

Otoni, C.G., De Moura, M.R., Aouada, F.A., Camilloto, G.P., Cruz, R.S., Lorevice, M.V., Soares, N.F.F., Mattoso, L.H.C., 2014. Antimicrobial and physical-mechanical properties of pectin/papaya puree/cinnamaldehyde nanoemulsion edible composite films. Food Hydrocoll. 41, 188-194.

Otoni, C.G., Avena-Bustillos, R.J., Azeredo, H.M.C., Lorevice, M.V., Moura, M.R., Mattoso, L.H.C., McHugh, T.H., 2017. Recent advances on edible films based on fruits and vegetables - a review. Compr. Rev. Food Sci. Food Saf. 16, 1151-1169.

Oyama, K.-I., Yamada, T., Ito, D., Kondo, T., Yoshida, K., 2015. Metal complex pigment involved in the blue sepal color development of hydrangea. J. Agric. Food Chem. 63, $7630-7635$.

Pascual-Teresa, S., Sanchez-Ballesta, M.T., 2008. Anthocyanins: from plant to health. Phytochem. Rev. 7, 281-299.

Patel, H.A., Somani, R.S., Bajaj, H.C., Jasra, R.V., 2007. Preparation and characterization of phosphonium montmorillonite with enhanced thermal stability. Appl. Clay Sci. 35, 194-200.

Patras, A., Brunton, N.P., O'Donnell, C., Tiwari, B.K., 2010. Effect of thermal processing on anthocyanin stability in foods; mechanisms and kinetics of degradation. Trends Food Sci. Technol. 21, 3-11.

Pinto, A.M.B., Santos, T.M., Caceres, C.A., Lima, J.R., Ito, E.N., Azeredo, H.M.C., 2015. Starch-cashew tree gum nanocomposite films and their application for coating cashew nuts. LWT Food Sci. Technol. 62, 549-554.

Ribeiro, H.L., Oliveira, A.V., Brito, E.S., Ribeiro, P.R.V., Souza Filho, M.S.M., Azeredo, H.M.C., 2018. Stabilizing effect of montmorillonite on acerola juice anthocyanins. Food Chem. 245, 966-973.

Rojas-Graü, M.A., Avena-Bustillos, R.J., Olsen, C., Friedman, M., Henika, P.R., MartínBelloso, O., Pan, Z., McHugh, T.H., 2007. Effects of plant essential oils and oil compounds on mechanical, barrier and antimicrobial properties of alginate-apple puree edible films. J. Food Eng. 81, 634-641.

Romero-Bastida, C.A., Bello-Pérez, L.A., Velasquez, G., Alvarez-Ramirez, J., 2015. Effect of the addition order and amylose content on mechanical, barrier and structural properties of films made with starch and montmorillonite. Carbohydr. Polym. 127, 195-201.

Schreiber, H.D., Swink, A.M., Godsey, T.D., 2010. The chemical mechanism for $\mathrm{Al}^{3+}$ complexing with delphinidin: a model for the bluing of hydrangea sepals. J. Inorg. Biochem. 104, 732-739.

Sigurdson, G.T., Robbins, R.J., Collins, T.M., Giusti, M.M., 2016. Evaluating the role of metal ions in the bathochromic and hyperchromic responses of cyanidin derivatives in acidic and alkaline pH. Food Chem. 208, 26-34.

Slavutsky, A.M., Bertuzzi, M.A., Armada, M., García, M.G., Ochoa, N.A., 2014. Preparation and characterization of montmorillonite/brea gum nanocomposites films. Food Hydrocoll. 35, 270-278.

Tachibana, N., Kimura, Y., Ohno, T., 2014. Examination of molecular mechanism for the enhanced thermal stability of anthocyanins by metal cations and polysaccharides. Food Chem. 143, 452-458.

Tan, B., Thomas, N.L., 2017. Tortuosity model to predict the combined effects of crystallinity and nano-sized clay mineral on the water vapour barrier properties of polylactic acid. Appl. Clay Sci. 141, 46-54.

Tseng, C.L., Su, W.Y., Yen, K.C., Yang, K.C., Lin, F.H., 2009. The use of biotinylated-EGFmodified gelatin nanoparticle carrier to enhance cisplatin accumulation in cancerous lungs via inhalation. Biomaterials 30, 3476-3485.

Wang, J.S., Luo, H., Billam, M., Wang, Z., Guan, H., Tang, L., Goldston, T., Afriyie-Gyawu, E., Lovett, C., Griswold, J., Brattin, B., Taylor, R.J., Huebner, H.J., Phillips, T.D., 2007. Short-term safety evaluation of processed calcium montmorillonite clay (NovaSil) in humans. Food Addit. Contam. 22, 270-279.

Xie, W., Gao, Z., Liu, K., Pan, W.P., Vaia, R., Hunter, D., Singh, A., 2001. Thermal characterization of organically modified montmorillonite. Thermochim. Acta 367. 368, 339-350.

Yoshida, K., Mihoko, M., Kondo, T., 2009. Blue flower color development by anthocyanins: from chemical structure to cell physiology. Nat. Prod. Rep. 26, 857-964.

Zheng, J.P., Li, P., Ma, Y.L., Yao, K.D., 2002. Gelatin/montmorillonite hybrid nanocomposite. I. Preparation and propertiees. J. Appl. Polym. Sci. 86, 1189-1194. 